\title{
GENERAL EXERCISES.
}

There has been enough discussion of the need of a social habit of mind and social service to convince one that the child in the gracies, or the student in college, who does nothing more in the pursuit of an education than attain good scholarship is choosing too narrow a course. According to Cecil Rhodes, scholarship should possess the worth of three points where ability in sports, manhood, and service to others count as seven. This judgment of an acute man of the world probably approximately represents that of observant peopie in general. A good education includes all these factors, and even some other equally important ones, perhaps.

There are always some persons who, owing to their native tendencies, home environment, or other peculiar advantages, enjoy a variety of experience sufficient to develop them freely in all these respects. But a majority seem dependent upon the schools for their estimate of relative values and their corresponding growth. They may be properly broadened through the influence of the school, or may easily be led to ignore those opportunities for improvement that are not distinctly bookish.

There has been a marked tendency in the latter direction in most schools. Certainly the average adult will testify that he never received the impression from the school that scholarship is only one in a half-dozen elements in a good education, and most of us have had to be jostled by the world for a number of years before becoming sufficiently freed from the schoolroom atmosphere to conceive this fact.

It is a vital matter, therefore, to consider when and how the common school plans to impress upon its pupils the several essentials in a good education besides scholarship, and to give to each its approximate relative value.

Two changes of recent years tend in this direction. In the first place, the greatly increased amount of construction exposes 
the relation of theory to practice in much the ratio that is found in the world in general; and, in the second place, the recognition of actual service to others as the true end-point of instruction, rather than the mere acquisition of knowledge or skill, promises to make school work less theoretical. The two will help much to make school work a healthy representative of real life.

But, no matter how good the instruction in the individual studies may be, it is almost sure to overemphasize knowledge, and thereby to underestimate other good things in life. This must be the case, not only on account of established practice, but because a great number of the chief topics of common interest find no definite place in the separate studies, as these are now constituted. For example, "one's fondness of and success in manly outdoor sports," as Rhodes put it, which he regarded as two-thirds as important as "one's literary and scholastic attainments," are ordinarily unprovided for in the curriculum. Even where physical education has a definite place on the program, its purpose is only such exercises as may lead to health, rather than a deep-seated love of sport and skill in playing games. Yet a love for sport is of immense value, like a love for literature, being the best guarantee of physical health of body and mind, just as the latter love insures mental life and moral health. And, owing to this omission, it is not uncommon to meet adults who admit never having learned to play well with others, or to enjoy such play.

Sociability is another quality that finds no definite place in the curriculum. Many children habitually isolate themselves from companions during intermission, for the sake of a little more study, or because they cannot take part in the enjoyment, or because they have learned to contemn conversation as an idle employment. Yet, if either geography or sociability had, for some reason, to be neglected, no one would long hesitate in allowing the neglect to fall on the former. How many other things might be named that are extremely important, but that do not fall legitimately within any of the studies!

Where and when are such matters to be treated? The school is not, of course, responsible for everything; but, since good 
character is its aim, it must place the leading elements of character before its pupils, and must develop fair appreciation of their relative values. What better provision is there for this, and for much allied work, than that found in the general exercises of the school?

General exercises would thus assume a very important place, and I am convinced that that is their due. Wrile they should avoid duplicating the studies, they should broaden the child's horizon much beyond that of ordinary instruction, and present the elements of good character to pupils concretely and in proper perspective. To do this well would require much time and planning, and would make the general exercises so prominent that they, more than any other kind of work, might indicate the true nature of the school.

Only by some such arrangement can the personality of a forceful teacher find opportunity for full expression. The studies furnish such an outlet to some extent; but a broadly interested leader needs many other occasions also. One to whom no topics of worth occur for such times stands self-condemned as leading too narrow a life.

The college feels this need, just as does the school. College students very often remark on the narrowness of their individual studies, and long for some agency by which they may be brought into closer touch with a larger world. But the school can solve the problem more easily than the college, because its conditions are simpler. The first requisite, however, in either case is to take the question seriously and put an abundance of work on its solution. Some inkling of the possible benefits from such efforts have been suggested to very many persons by the morning exercises in the old Cook County Normal School under the régime of Colonel Parker.

What kind of work might general exercises properly include? First of all, worship, where the law of the state does not forbid. But a perfunctory reading of the Scriptures and repetition of a prayer probably dull the spirit of reverence rather than quicken it. Why do many of the better schools apply the principles of psychology most earnestly to instruction in nature-study, etc., 
and apparently forget the existence of such principles when it comes to worship of the Lord? I find no explanation of the fact, except that principals and superintendents-who are the leaders in devotional exercises-ordinarily give so little instruction that they do not hold themselves amenable to the same laws for good teaching as their own teachers must follow. Good pedagogy would seldom allow a chapter in the Bible to be read without comment, and very often the remarks should precede, rather than follow, the reading. An occasional short, earnest prayer by the leader is also greatly needed, to lend meaning to the repetition of other prayers. Freshness and life in worship at school are especially important, because worship elsewhere is usually so dull to children. Variety in the form of exercises thus becomes a law; but close sequence within one day's exercises, and from day to day as well, is as binding here as elsewhere. A certain school containing children of ages from six to twenty years recently gave a fine example of what should not be, by the following program: ( I ) a love scene from Wagner's Walküre, on the piano-sensuous in the extreme; (2) a pietistic hymn; (3) the Lord's prayer; (4) a Vedic hymn read, without introductory remarks; (5) a church hymn.

In school, if anywhere, is there an opportunity to teach the real purpose of music in connection with worship; and with that object there should be the closest possible correlation of thought of songs with that of the other exercises, and all together should form a unit.

The occasional omission of Scripture and prayer, for the sake of time, to introduce a "moral talk" seems to me also fitting. The teaching world has grown skeptical of regularly scheduled moralizings; but the need of forcible talks on conduct has not yet been outlived; and fitting opportunities for them are still abundant. A proper utilization of such occasions is the highest mission of the teacher.

There is a great waste of opportunity in not calling in a stranger for a talk occasionally. Very frequently persons are within reach who are well fitted to discuss some important event, to express a personal view about some moral question, etc., in a 
simple, entertaining manner. The risk of an occasional failure should not dissuade teachers from such a course either, because pupils tire of school routine and personalities, and a few words from outside, supporting ideas perhaps already presented, have a very restful, stimulating effect. The failures in these efforts would be less frequent than they are, too, if definite suggestions were given to such speakers as to the topics that might prove peculiarly fitting. If, for example, a competent man were asked to talk to a school on "How to Read Newspapers," or on "Some of the Ways for a Family to Find Entertainment Together of an Evening," or on the "Worth of Sociability," the greatest obstacle to consenting to speak might be overcome, and unusual profit would be likely to result. Teachers who are watchful of the needs of their pupils would not fail to carry such topics in stock. The introduction of strangers to the school-always carefully coached-might well constitute one of the most important parts of general exercises. At these times, too, parents could be especially invited, the occasion thus furnishing a means of identifying them with the school.

But a good part of the exercises should be given by the children themselves. In the ordinary recitations the interest centers largely in each child's ability to "take in" what the teacher or book presents. The spirit is individualistic. The general exercises should be far more altruistic, expecting individuals and groups to make frequent contributons for the entertainment and improvement of their companions. Thus, committees might make reports; one class might offer an entertainment devised by itself; a larger group might sing songs newly learned; quotations, reports on favorite books read, and debates might be listened to. The work there done would be of a much broader character than that of the ordinary hecitation period, and would throw into perspective the facts of instruction. The last benefit would certainly result if the teacher kept relative values well in mind, as suggested at the beginning of this article, and saw to it that the right emphasis was laid on the main qualities that lead to usefulness and efficiency.

Large numbers themselves are a valuable aid in cultivating 
the altruistic spirit. The group-feeling is stimulated whenever a child finds hinself one of a great many engaged in a common end. To the extent that his own insignificance is impressed upon him, his capacity for devotion to the general good is increased. Under the influence of numbers, therefore, altruistic appeals are most likely to be made with success; the need of unity is then apparent, and right school traditions may become established. In other words, a peculiar and very valuable kind of work can be best accomplished by bringing many pupils together.

I have attempted to show that general exercises, having a special purpose, are worthy of time on the program and very careful preparation. Whether they should be planned for daily, should come always at the same hour, and should cause the entire school to be assembled, are questions the answers to which might vary according to conditions. But, certainly, carefully prepared exercises coming once per week are preferable to $a$ very brief daily exercise. Many objects, too, can be better accomplished in the smaller groups, consisting of children from one or two or three rooms, than in an assembly of all grades. And some flexibility of the program is highly desirable, whereby an ordinary recitation period of a grade may be given over to a general exercise, owing to a need that has unexpectedly arisen.

Frank M. McMurry.

Teachers College,

Columbia University. 